\title{
CONVERSATIONAL MOVES IN ACE VENTURA MOVIE
}

\author{
*Yaebesi Gulo \\ **Citra Anggia Putri, S.S., M.Hum. \\ **Juli Rachmadani Hasibuan, S.S., M.Hum.
}

\begin{abstract}
Gulo, Yaebesi. 2131220020. Conversational Moves in Ace Ventura Movie. A Thesis. English Education and Literature Department, Faculty of Languages and Art. State University of Medan. 2018.

This study deals with Conversational Moves in Ace Ventura Movie. The purpose of the study is to find out the moves are played by the main character of Ace Ventura movie $1^{\text {st }}$ series, describing how the moves are played by the characters of Ace Ventura movie $1^{\text {st }}$ series and to find out the reason why the Moves are played in the way it is. The data were analyzed based on the Structure of interaction theory by Martin (1992). The analysis showed the moves are played by the main character of Ace Ventura Movie are K1 (primary knower) 37,9 \%, K2 (secondary knower) 21,07 \%, K1f (primary knower follow-up) 4,64 \%, K2f (secondary knower follow-up)13,6 \%, A1 (primary actor) $3.2 \%$, A2 (secondary actor) 7,14 \%, A1f (primary actor follow-up) 0,35\%, A2f (secondary actor follow-up), Da1 (delay primary actor) 0,35\%, Bch (backchannel) 0,35\%, Cl (clarification) $0,35 \%, \mathrm{Cf}$ (confirmation) $3,2 \%$, Rcf (response to confirmation) $4,64 \%$ and $\mathrm{Ch}$ (challenging) $0,71 \%$. The moves that are played by the characters is dynamic because the speakers on that dialogue staged clarification, confirmation, back-channel and challenging move on the dialogue.
\end{abstract}

Keywords: Conversational Moves, Dynamics of Exchange.

\footnotetext{
* Graduate Status

** Lecturer Status
} 


\section{INTRODUCTION}

Background of The Study

Human as social being, need to interact with other people. By using language they communicate each other in their interaction to transfer ideas, thought, and feeling, bacause language is means of communication. Communication itself can be defined as the process of transmitting information and common understanding from one person to another (Keyton, 2011). Two common elements in every communication exchange are the sender and the receiver. In our daily life the sender is a person who has a need or desire to convey an idea or concept to others. The receiver is the individual to whom the message is sent. The message is the outcome of the encoding, which takes the form of verbal, nonverbal, or written language. The message is sent through a medium or channel, which is the carrier of the communication. The medium can be a face-to-face conversation, telephone call, e-mail, or written report. The receiver decodes the received message into meaningful information.

Considering those various functions of the language mentioned above, it can be concluded that language function is as a tool of communication. Related to this, in doing communication or exchange there is a role that is played by the speaker and the hearer which is called move. Saragih, (2014) defined move as the function or role played by speaker (addresser) in a conversation in his or her orientation to the function or role played by the hearer (addressee) and with respect to the commodity being exchanged. 
The realization of move in a conversation can be seen in the dialogue that was taken from the Ace Ventura movie bellow:

\section{K1 MARTHA}

No, but I wanted to tell you, when I lost my Cuddles, I hired a pet detective.

\section{Cf PODACTER}

A what?

\section{Rcf MARTHA}

A pet detective.

From the dialogue above it can be seen that the dialogue between the interlocutors does not progress smoothly, there`s an interuption in it, where Podacter makes confirmation to what has been said by Martha. Based on this case the researcher will study about the conversational moves in Ace Venura Movie $1^{\text {st }}$ series. The researcher will find out the moves that are played by the main character on that movie, then describing how the moves are played by the characters of Ace Ventura movie $1^{\text {st }}$ series and explaining why the moves are played in the way it is. The researcher chooses this topic because this topic is interesting to be learned, through the research result the readers are able to understand about the exchange structures of Ace Ventura Movie, which are made up by moves. On the other hand, in learning to interact particularly for those English is a foreign language, one should learn not only grammatically correct sentence but also patterns of exchanges. 


\section{REVIEW OF LITERATURE}

\section{Discourse Analysis}

Discourse analysis is the study of the ways in which language is used in texts and contexts (Gee, 2010). It aims to study and anayze the use of discourse. Analysis of discourse looks not only at the basic level of what is said, it takes into consideration the surrounding social and historical contexts. The discourse analysis is typically based on the linguistic output of some other. More typically, the discourse analysis is taken from written texts or tape recordings. (Halliday, 2002 in Simangunsong, 2015) argues that metafunctions is inherently functional. His early papers on the grammar of english make reference to the funtional components of language, as generalized uses of language, which since they seem to determine the nature of the language system, require to be incorporated into our account of that system. Functional organization of language determines the for taken by grammatical structure.

Halliday refers to his functions of language as metafunctions. He proposes three general functions, they are the ideational metafunction construing human experience. Second is the interpersonal metafunction relates to a text's of tenor or interactivity, like field, tenor comprises three component areas: the speaker/writer personal, social distance, and relative social status. The third is textual metafunction, it relates to mode, the internal organization and communicative distance. 


\section{Move}

Move is defined as the function or role played by a speaker (addresser) in a conversation in its relation to the function or role played by the hearer (addressee) and the commodity being exchanged (Saragih, 2014). This means the move is a unit which has a function relation to the progression of the conversation. A conversation as in (1) below A is raising a question, namely asking information and $\mathrm{B}$ is responding to the question, namely providing information. Thus, raising question implies giving answer or reply. The move made by $\mathrm{A}$ is termed as $\mathrm{k} 2$ (secondary knower move), while B that knows the information termed as k1 (the primary knower move). Structure of $\mathrm{k} 2 \Lambda \mathrm{k} 1$ is seen as the basic unit of conversation or exchange in which $\mathrm{k} 2$ is raising question whereas $\mathrm{k} 1$ providing the answer.

1. k2 A : Did you go to the party?

k1 B : yes.

The stucture in English may be $\mathrm{k} 2 \Lambda \mathrm{k} 1 \Lambda \mathrm{k} 2 \mathrm{f} \Lambda \mathrm{k} 1 \mathrm{f}$ as in example (2) below:

2. k2 A : did you go to the party?

k1 B : yes.

k2f A : thank you.

k1f B : my pleasure.

Where:

k2 : secondary knower, the move is raising question.

$\mathrm{k} 1$ : primary knower, the move is responding to the question.

$\mathrm{k} 2 \mathrm{f}$ : secondary knower follow-up, the move is adding respond to the $\mathrm{k} 1$. 
k1f : primary knower follow-up, the move is responding to the aditional respond of $k 2 f$.

The structure of exchange or conversation in english is (k2) $\Lambda \mathrm{k} 1 \Lambda$ (k2f) $\Lambda$ (k1f). Where the aspect in brackets is optional (Saragih 2004). Thus, the structure of conversation may be either one of the followings:

a. $\mathrm{k} 1$ : primary knower move.

b. k2 $\Lambda \mathrm{k} 1$ : secondary knower move followed by primary knower move.

c. k2 $\Lambda \mathrm{k} 1 \Lambda \mathrm{k} 2 \mathrm{f}$ : secondary knower move followed by primary knower move followed by secondary knower follow-up.

d. k2 $\Lambda$ k1 $\Lambda$ k2f $\Lambda$ k1f : secondary knower move followed by primary knower move followed by secondary knower follow-up then followed by primary knower follow-up move.

e. k1 $\Lambda$ k2f : primary knower move followed by secondary knower follow-up move.

f. k1 $\Lambda$ k2f $\Lambda$ k1f : primary knower move followed by secondary knower followup move followed by primary knower follow-up move.

Another possibility is that the structure is:

g. $((\mathrm{dk} 1) \Lambda \mathrm{k} 2) \Lambda \mathrm{k} 1 \Lambda(\mathrm{k} 2 \mathrm{f}) \Lambda(\mathrm{k} 1 \mathrm{f})$ : delay primar knower move followed by secondary knower move followed by followed by the secondary follow-up move then followed by the primary knower follow-up move. (Saragih, 2004) The move of $\mathrm{dk} 1$ indicates a speaker who seems to ask information but she or he really knows the information. thus, she or he delays telling the information. 
this is often found in the classroom quiz where the teacher asks question to the students. The teacher knows the answer to the question and it is the students who are to supply the answer. To exemplify, interaction in example (3) below indicates exchange structures where information and goods and services are negotiated.

3. $\mathrm{dk} 1 \mathrm{~A}$ : what is the currency of indonesia?

k2 B: rupiah

k1 A: right

As an analogy to the interaction in information an interaction on goods and services has the following structures

((da1) $\Lambda$ a1 $\Lambda$ (a2f) $\Lambda$ (a1f) : delay primary actor move followed by primary actor move followed by the secondary actor move then followed by the primary actor move.

Which :

da1 : delay primary actor (the person who delays giving goods and services)

a1 : primary actor (the person who demands goods and services)

a2 : secondary actor (the person who demands goods and services )

a2f : secondary actor follow-up

a1f : primary actor follow-up

The following conversation employs da1

4. da1 A : can I get you a beer?

a2 B : yes, please

a1 A : here you are 


\section{Dynamics of Exchange}

An exchange sometimes does not progress smoothly. A conversation does not necessarily like the structures previously presented. Some hindrances may occur to the smoothness of an interaction. In reality a speaker often stages challenges, ask clarifications and confirmations serve as the dynamics of interaction (Saragih, 2014).

Example:

A2 : Let`s go to a movie.

A what?

A movie.

A1 : okay.

In this example the $\mathrm{A} 2 \wedge \mathrm{A} 1$ exchange is interrupted by an additional adjacency pair. It has function of clarifying what has been proposed by the secondary actor.

\section{a. Tracking}

In doing exchange, interlocutors have to agree on what they negotiating about, consequently, any comprehensive treatment of conversational structure include discussion of the resources used to ensure that the experiental meaning under consideration is shared. One common signal of this is the back-channel (bch), which is used to monitor the dialogue, reassuring interlocutors that negotiaton is proceeding smoothly (this phenomenon is most prominent in telephone conversations). These are realised paralinguistically ( $\mathrm{hm}, \mathrm{mm}$, etc.) and 
by polarity items (yes, yeah, no). Ventola (1987) illustrates back-channel moves as follows:

1. k1 Server : say it you're looking at fourteen days, bch Cient : hm.

k1 Server : at Sanyor beach, bch Client : Yes.

Back-channel moves (Bch) contrast with other tracking moves, all of which have a pottential response. This is because other moves occur where there is some doubt as to the experiential meaning being negotiated. This doubt may be on the part of the current speaker. Ventola`s above example continues as follows:

2. check Server : //2 fourteen days, right // rcheck Cient: uhm.

Here the server checks on information included in the first class of what is becoming a long clause complex to make sure two weeks is what the client intends. Other tracking moves involve a change of turns. These can be divided into those which explore experiental meaning coded in the previous turn and those which elaborate upon it. Simplifying slightly, Ventola`s example of clarifying moves, which elaborate experiential menaing, is as follows:

3. k2 : Client : what time flights then go to sydney tomorrow?

cl : Server : //2 er morning or afternoon now//

rcl : Client : uh, mid-morning, early afternoon.

k1 : Server : uh we, you`ve got a 9:30 and 10:15...

The rest of the tracking moves simply explore that experiential meaning that has already been added. Where this meaning has been completed missed, 
interloutors request a complete replay, using items such as what, pardon, huh, sorry, eh, i beg your pardon and so on:

4. k2 does she have Peter Pan?

cf $>$ what?

rcf $\$$ does she have Peter Pan?

k1 yes

Sometimes repetition shows that in fact the experiential meaning of the preceding move has been misheard, it will be replayed, giving rise to sequences such as the following:

5. k2 do you have Snow White?

cf $\longrightarrow$ the Snow Queen.

rcf $\gg$ no

rp $\hookrightarrow$ Snow White.

$\operatorname{rrp} \rightarrow$ oh.

k1 no.

Tracking moves are found at any point in exchange structure, although the more experiential meanings are given move makes explicit, the more likely it is to be misunderstood and so tracking is more common at the beginning of an exchange than at the end.

\section{b. Challenging}

The second type of interruption is challenging (aborting move), it has function to extricate interlocutors from an exchange. With calls and greetings, they refuse attention:

1. Gr hi.

$\mathrm{Ch}$ piss off 
Call john

Ch (ignore)

With negotiating exchanges, escape trategies are sensitive to what is being exchanged. Where this is an opinion, the interlocutor must refuse to grade, there avoid a sympathising reaction:

2. Ex a pity

Ch none of my business.

With goods \& services, it is necessary to stop the primary actor accomplising the non-verbal action hich may accompany (proffer) or follow from (promise) te A1 move.

3. Da1 shall i get you a drink?

Ch no tanks.

\section{RESEARCH METHODOLOGY AND FINDINGS Methodology}

The research was conducted by applying the descriptive method with qualitative approach. Kothari (2004) stated qualitative research is concerned with qualitative phenomenon, for instance phenomena relating to or involving quality or kind. Qualitative research is especially important in the behavioural sciences where the aim is to discover the underlying motives of human behaviour. Through such research we can analyse the various factors which motivate people to behave in a particular manner or which make people like or dislike a particular thing. 


\section{Technique of Data Analysis}

The data was analyzed by some steps: first, identifying the moves that were played by the main character in Ace Ventura Movie $1^{\text {st }}$ series. Second, classifying the types of moves that were played by the main character in Ace Ventura Movie $1^{\text {st }}$ series. Third, describing how the moves were played by the characters in Ace Ventura Movie $1^{\text {st }}$ series based on the J. R. Martin theory about the structure of interaction. In which structure of interaction can be structural or dynamic. Fourth, explaining why the moves were played in the ways they were based on the context of situation of the interaction among the characters and based on the theory of the structure of interaction by J.R Martin (1992), he states that one basic problem with the adjacency pair notion is that interacts do not always come in pairs or an exchange does not progress smoothly, some hindrances or obstructions may occur to the smoothness of an interaction. In reallity a speaker often stages challenges, asks clarification and requires confirmation of the interlocutor. The moves of challenge, clarification and confirmation and the responses to them do not form the exchange structures. In other word they are not structural rather they are external to the exchange structure. 


\section{Findings}

After analyzing the data, the findings are presented as follows:

1. The moves that are played by the main character in Ace Ventura movie.

Based on the research analysis, the researcher found 14 types of moves that are played by the main character of Ace Ventura Movie $1^{\text {st }}$ series, those are K1 (primary knower) 37,9 \%, K2 (secondary knower) 21,07 \%, K1f (primary knower follow-up) 4,64 \%, K2f (secondary knower follow-up)13,6 \%, A1 (primary actor) $3.2 \%$, A2 (secondary actor) 7,14\%, A1f (primary actor follow-up) $0,35 \%$, A2f (secondary actor follow-up), Da1 (delay primary actor) 0,35\%, Bch (backchannel) $0,35 \%, \mathrm{Cl}$ (clarification) $0,35 \%, \mathrm{Cf}$ (confirmation) $3,2 \%, \mathrm{Rcf}$ (response to confirmation) $4,64 \%$ and $\mathrm{Ch}$ (challenging) $0,71 \%$. The total number of the moves that are played by the main character are 280 moves.

2. How the moves are played by the characters in Ace Ventura Movie.

Based on the research analysis, the researcher found the dialogue among the characters was played dynamic.

3. Why the moves are played in the way it is.

The dialogue was played dynamic because the interlocutors on the dialogue staged clarifications, confirmation, back-channel and challenging move. Clarification, back-channel and confirmation serve as tracking, while the challenging move is to abort or to extricate the interlocutor from the exchange. 


\section{CONCLUSIONS AND SUGGESTIONS}

\section{Conclusions}

After analyzing the data, conclusions are drawn as follows:

1. The moves that are played by the main character of Ace Ventura Movie $1^{\text {st }}$ series are: K1 (primary knower) 37,9\%, K2 (secondary knower) 21,07 \%, K1f (primary knower follow-up) 4,64 \%, K2f (secondary knower follow-up)13,6 \%, A1 (primary actor) $3.2 \%$, A2 (secondary actor) 7,14\%, A1f (primary actor follow-up) $0,35 \%$, A2f (secondary actor follow-up), Da1 (delay primary actor) 0,35 \%, Bch (backchannel) 0,35\%, $\mathrm{Cl}$ (clarification) $0,35 \%, \mathrm{Cf}$ (confirmation) $3,2 \%$, Rcf (response to confirmation) 4,64\% and Ch (challenging) 0,71\%. And the moves among the characters was played dynamic.

2. From the data findings, it is found that the moves are played dynamicly by the characters. There are 33 times the moves are played dynamic. Those dyamic moves are Bch (back-channel), $\mathrm{Cl}$ (clarification), $\mathrm{Cf}$ (confirmation), Rcf (response to confirmation) and $\mathrm{Ch}$ (challenging).

3. The moves were played dynamic because the interlocutors did not always agree on what they negotiating about. Consequently, any comprehensive treatment of conversational structure must include discussion of the resources used to ensure that the experiential meaning under consideration is shared. On the dialogue, the speaker monitoring the dialogue to reassure interlocutors that negotiaton is proceeding smoothly, the speaker elaborates experiential meaning, the speaker simply explores the experiential meaning that has already been added. In which, 
this meaning has been completed missed and the speaker extricates interlocutors from an exchange (they refuse attention, refuse to grade, avoid a sympathising reaction and to stop the primary actor accomplising the non-verbal action).

\section{Suggestions}

1. English Literature students

The writer suggests to the English Literature students to study about the exchange structures which are made up by moves in learning to interact particularly in English by realizing the natural flow of interaction.

2. The next researcher

The writer suggests to the next researcher to find another object of their research and it is suggested to the next researcher to analyze not only moves but to analyze the dialogue at the level of semantics (speech function) and lexicogrammar (mood). 


\section{REFERENCES}

Brown, G. \& Yule, G. 1983. Discourse analysis. Cambridge: Cambridge University Press

Cockayne, M. 2010. Applying the Sinclair and Coulthard model discourse analysis to a student-centered EFL classroom. Birmingham University TEFL/TESL ODL module 4 assignment.

Dahal, B. 2010. Analsis of Spoken Discourse Pattern in Nepali ELT Classes. Vol. 15 Nepal: Journal of NELTA

Eggins, S. 1994. An Introduction to Systemic Functional Linguistics.London: Pinter.

Eggins, S.\& Slade, D. 1997.Analyzing Casual Conversation.London: Cassell.

Halliday, M. A. K., 1994. An introduction to functional grammar, $3^{\text {rd }}$ Edition. London: Edward Arnold.

Halliday, M. A. K. and Ruqaiya Hasan 1989.Language, context, and text: aspects of language in a social semiotic perspective. New York: Oxford University Press.

Hartman, R. R. K. and Stork, F. C, 1972.Dictionary of Language and Linguistics.London: Applied Science.

Hoby, A. S. 1995. Oxford Advanced Learners`s Dictionalry. Oxford University Press.

Khothari, C. R. 2004. Research Methodology: Metods and Techniques. $2^{\text {nd }}$ edition. New Dehi: New Age International Publishers.

Lunenberg, F. C. 2010, Communication: The Process, Barriers, and Improving Effectiveness. Vol.1. 1. texas: journal of Schooling

Martin, J.R. 1992. English Text: Systems and Structures. Amsterdam: John Benjamins.

O`Donnell, M.1990 “A Dynamic Model of Exchange” Word, vol. 41,3 December 1990

O`Donnell, M. 1992 “Dynamics Representation of Exchange Structure” Version: 1992.

Samosir, R.S.C.U. 2010 “Move Analysi In Mario Teguh's Talk Show in Metro $T V$ '. Thesis. Medan: FBS UNIMED

Saragih, A. 2014.Discourse Anlysis. Medan: FBS UNIMED (unpublished).

http://www.dailyscript.com/scripts/ace_ventura_shoot.html. Accessed on 2nd July 2017. At 11:07 pm

https://simple.wikipedia.org/wiki/Movie. Accessed on $13^{\text {th }}$ novemer 2017.

At 11: $38 \mathrm{pm}$. 